\section{Severe Asthma Units Accredited by the Spanish Society of Allergology and Clinical Immunology (SEAIC): Experience and Future}

Delgado Romero J ${ }^{1,6}$, Miralles López JC ${ }^{2,6}$, Álvarez Puebla $\mathrm{M}^{3,6}$, Fernández Ibáñez E ${ }^{4,7}$, Habernau Mena $\mathrm{A}^{5,6}$

${ }^{1}$ Allergy Service, Hospital Universitario Virgen Macarena, Sevilla, Spain

${ }^{2}$ Allergy Service, Hospital Universitario Reina Sofia, Murcia, Spain

${ }^{3}$ Allergy Service, Complejo Hospitalario de Navarra, Pamplona, Spain

${ }^{4}$ Allergy Service, Hospital Universitario, Araba, Spain

${ }^{5}$ Allergy Service, Complejo Hospitalario de Mérida, Mérida, Spain

${ }^{6}$ Asthma Committee, SEAIC

${ }^{7} \mathrm{CME}$ Committee SEAIC

J Investig Allergol Clin Immunol 2021; Vol. 31(2): 182-184 doi: 10.18176/jiaci.0618

Key words: Severe asthma units. Accreditation process. SEAIC.

Palabras clave: Unidades Asma Grave. Proceso acreditación. SEAIC.

\section{To the Editor:}

Severe asthma is currently estimated to affect $3 \%$ to $10 \%$ of asthmatic adults [1,2] and up to $2.5 \%$ of asthmatic children [3]. Management of these patients has a major impact on health care costs and the consumption of resources: previous studies in Spain have estimated the cost of severe asthma at $€ 8554$ per patient per year [4].

Therefore, while it is necessary to perform a rigorous and systematic study in patients who present chronic symptoms of severe asthma, the particularities of the disease in some cases require the study to be individualized. These 2 apparently discordant needs have led to the drafting of consensus guidelines advising that severe asthma should be identified and controlled in specialized and preferably multidisciplinary clinics $[5,6]$. This reality was recently reinforced with the development of specific biological drugs for the treatment of patients with severe asthma based on very well-defined indications and follow-up [7].

In 2015, the Asthma Committee of the Spanish Society of Allergology and Clinical Immunology (SEAIC) addressed the task of establishing the necessary requirements for the accreditation of different levels of care for severe asthma units throughout Spain.

The objectives of this process were to improve the clinical care of patients with severe asthma by unifying criteria of good clinical practice, to structure and facilitate clinical management, and to promote research into severe asthma. Another fundamental objective was to improve the education of the asthmatic patient: it is known that adequate training increases adherence and disease control [8].

The accreditation levels were Basic Severe Asthma Unit (SAU) and Excellence SAU. The evaluation was based on essential, recommended, and excellence criteria. According to the fulfillment of these criteria, the SAUs were accredited as Basic or Excellent. The criteria required for the accreditation can be consulted at https://www.seaic.org/profesionales/ acreditacion-unidades-de-asma-grave and are summarized in the Table.

Briefly, the flow of patients to the SAU must come from both outside and inside the hospital. It is important to inform those responsible for specialized and primary care about the existence and function of the SAU, and the flow of asthmatic patients between primary and specialized care and the asthma unit must be bidirectional. The SAU is recommended to work as a multidisciplinary unit in close contact with related services, such as pneumology, ENT, gastroenterology, and psychiatry.

The units must follow the SEAIC guidelines on asthma management, and their service portfolio must be in line with these recommendations.

As specified in the Spanish Guidelines for Asthma Management [6], the diagnosis of this disease requires a respiratory history compatible with the disease and positive results in functional testing. An SAU must have the necessary tools to avoid false diagnoses.

The endo- and phenotype must be taken into consideration when planning treatment in patients with severe asthma, since the therapeutic approach differs in each case. Therefore, the SAU must have the necessary tools to be able to distinguish between endo- and phenotypes of asthma.

Several comorbidities should be considered in patients with severe asthma, and some are relevant because they may result in misattribution of symptoms to asthma. Identifying and evaluating triggers for asthmatic symptoms (exposure to allergens and workplace chemicals, smoking, and frequent infections) is also important. The SAU must have the means to identify both comorbidities and aggravating asthma factors.

Furthermore, the SAU must provide effective education for the asthmatic patient based on a plan including the key skills for self-management of asthma: inhalation technique, medication adherence, a written action plan, and knowledge of the disease. In addition to scheduled care, the SAU must have the means for occasional treatment of patients who experience clinical worsening.

Five years after initiation of the program, 31 SAUs have been accredited ( 9 Basic and 22 Excellence). The accreditation program includes a periodic audit and a 5-year reaccreditation process. 
Table. Nonexhaustive Summary of Criteria for Accreditation of Basic and Excellent Severe Asthma Units

\begin{tabular}{lll}
\hline & Basic & Excellent \\
\hline $\begin{array}{ll}\text { Accessibility } \\
\text { and continuity }\end{array}$ & - Defined referral criteria & - Own service portfolio included in the \\
of care & Priority appointment of patients with uncontrolled asthma & Allergology Department portfolio \\
& Appointment program with adequate consultation time per & $\begin{array}{l}\text { Regular meetings with primary care and } \\
\text { specialist doctors in which the service }\end{array}$ \\
& portfolio is presented
\end{tabular}

Professionals and equipment

Continuous improvement and research

Service portfolio and patient evaluation
At least 1 allergist designated as responsible with accredited training in severe asthma

- Assigned nurse with experience in complementary tests for asthma

- Organization chart with the distribution of functions and responsibilities that is known by the members of the SAU and the Allergology Department

- The SAU works as a multidisciplinary unit: there are designated professionals from other specialties

- Clinical activity is based on the recommendations on asthma management in the guidelines of the Spanish Society of Allergology and Clinical Immunology.

- The SAU has the necessary instruments, furniture, and office equipment for the development of its service portfolio. All this material is inventoried and periodically reviewed

- The unit has the necessary means to treat an asthma attack or a severe allergic reaction

Clinical research and publications on asthma

- The SAU has annual information on the health care activity carried out

- The unit collaborates in teaching and continuous postgraduate training

The SAU has the means for the diagnosis of asthma and its classification

- It has the means for an adequate etiological diagnosis

- The unit provides training on asthma and inhalation techniques

- Administration of biological drugs and assessment of their efficacy and safety
The SAU holds regular meetings with reference specialists

- The unit uses a database that is updated in each consultation and enables the information to be used

- Support of a day hospital to carry out procedures recommended to be performed in a hospital environment

The SAU periodically conducts user satisfaction surveys

- The unit has a quality and continuous improvement plan

- Collaboration in multicenter studies with other SAU

The SAU has the equipment to carry out specific bronchial provocation tests

- Desensitization to nonsteroidal antiinflammatory drugs

- Cellularity of sputum

- Exercise test

- Nasal examination and function

- The unit conducts research with support staff
The accreditation program will continue to improve, with a review of the criteria, which will be adapted to the clinical and therapeutic situation of the asthma patient. In addition, network-based research work will be promoted in accredited SAUs. The program will continue to aim to improve clinical care and research in such a complex disease as severe asthma.

\section{Funding}

The authors declare that no funding was received for the present study.

\section{Conflicts of Interest}

The authors declare that they have no conflicts of interest.

\section{References}

1. https://ginasthma.org/wp-content/uploads/2020/04/GINA2020-full-report_-final-_wms.pdf; accessed at 18.04.2020

2. Almonacid Sánchez C, Melero Moreno C, Quirce Gancedo S, Sánchez-Herrero MG, Álvarez Gutiérrez FJ, Bañas Conejero D, et al. PAGE Study: Summary of a study protocol to estimate the prevalence of severe asthma in Spain using big-data methods, J Invest Allergol Clin Immunol. 2020 Jan 23;0. doi: 10.18176/jiaci.0483. Online ahead of print.

3. Ahmed $H$, Turner $S$. Severe asthma in children-a review of definitions, epidemiology, and treatment options in 2019. Pediatr Pulmonol. 2019:54:778-87.

4. Melero C, Quirce S, Huerta A, Uría S, Cuesta M. Economic impact of severe asthma in Spain: multicentre observational longitudinal study. J Asthma. 2019;56:861-87. 
5. McDonald VM, Vertigan AE, Gibson PG. How to set up a severe asthma service. Respirology. 2011;16:900-11.

6. https://www.gemasma.com/sites/default/files/2020-05/ GEMA_50_ok_.pdf; Last accessed 10.05.2020.

7. Davila I, Quirce S, Olaguibel JM. Selection of Biologics in Severe Asthma: A Multifaceted Algorithm. J Investig Allergol Clin Immunol. 2019;29:325-8.

8. Morel F, Ojanguren I, Cordovilla R, Urrutia I, Aguero R, Guerra J, et al. Two short interventions to reduce health care requirements in asthma patients. A multicentre controlled study (ASTHMACAP II). Med Clin. 2014;142:348-54.

- Manuscript received May 26, 2020; accepted for publication June 16, 2020.

\section{— Juan Carlos Miralles López}

Sección Alergología

Hospital General Universitario Reina Sofía

Avda. Intendente Jorge Palacios, 1

30003 Murcia

E-mail: juanc.miralles@carm.es 